\title{
WORK FUNCTION ESTIMATION OF BISMUTH DOPED ZNO THIN FILM
}

\author{
Brijesh Kumar Singh, Lucky Agarwal and Shweta Tripathi \\ Department of Electronics \& Communication Engineering, \\ Motilal Nehru National Institute of Technology, Allahabad-211004, India
}

\begin{abstract}
In this paper we report bismuth (Bi) doped $\mathrm{ZnO}$ based heterojunction devices. The p-type Bi doped $\mathrm{ZnO}$ thin films have been deposited on $n$ and p type silicon substrate using sol-gel spin coating method. The ptype nature of the deposited Bi doped $\mathrm{ZnO}$ thin films have been analyzed by hot point probe method. The electrical properties of the fabricated devices have been obtained from I-V characteristic measured using semiconductor parameter analyzer. Finally, the work function of Bi doped ZnO has been estimated from the electrical parameter obtained from I-V calculations.
\end{abstract}

\section{KEYWORDS}

Bi doped ZnO, P type ZnO, Sol-Gel, Work Function

\section{INTRODUCTION}

Innovative thinking and continuous modification have lead to the development of new generation of semiconductor devices. As far as the future of the semiconductor devices is concerned, $\mathrm{ZnO}$ has a major role to play in it as it is versatile and has interesting properties like resistivity control over the range of $10^{-3}-10^{-5} \Omega-\mathrm{cm}$, transparency in the visible range, high electrochemical stability, direct band gap (3.3 eV), absence of toxicity and abundance in nature [1-2 ]. Therefore, it can be stated that versatility of $\mathrm{ZnO}$ ranges from optical, electrical, piezoelectricity, ferromagnetic to gas sensing properties [ 3-5 ]. Further, large binding energy of $60 \mathrm{meV}$ as compared to $25 \mathrm{meV}$ of $\mathrm{GaN}$ makes $\mathrm{ZnO}$ technically efficient approving it for the field of optoelectronic applications. Thin films of $\mathrm{ZnO}$ can be used as a window layer and also as one of the electrodes in optoelectronic devices such as solar cells [6 ]. Along with this application, $\mathrm{ZnO}$ thin films have been used in varistors, gas sensors, solar cell transparent contact fabrication, etc [7-9 ]. It is worth mention here that requirement of an optoelectronic device is good quality pdoped $\mathrm{ZnO}$, and $\mathrm{p}$ - $\mathrm{n}$ junction, but developing a good quality p-doped $\mathrm{ZnO}$ is quite challenging because of its instability at room temperature [ 10-12 ]. Growth of p-type $\mathrm{ZnO}$ has been thought of in various ways including substitution of elements from Group IA or II B of periodic table on a $\mathrm{Zn}$ site, substitution of elements from Group VA on the $\mathrm{O}$ site, and codoping with donors and acceptors [13-15]. $\mathrm{Bi}$ is one of the important dopant to make $\mathrm{ZnO}$ p-type and is post-transition element that lies to the right of transition metals and to the left of the metalloids [16-17]. Bi doped $\mathrm{ZnO}$ leads to faster carrier migration. In this connection, using to the several attractive properties of $\mathrm{Bi}$ doped $\mathrm{ZnO}$ we have previously analyzed influence of $\mathrm{Bi}$ concentration in $\mathrm{ZnO}$ in terms of nature, structural and optical properties [18]. Further, using as the as obtained p-type Bi doped $\mathrm{ZnO}$ thin film we have reported the fabrication of Au based schottky diode [16]. Now, in the present paper p-type $\mathrm{Bi}$ doped $\mathrm{ZnO} / \mathrm{p}$-Si and p-type $\mathrm{Bi}$ doped $\mathrm{ZnO} / \mathrm{n}$-Si heterojunctions have been fabricated and work function of the $\mathrm{ZnO}$ film was estimated using the calculated electrical parameters of I-V characteristics.

DOI: 10.5121/antj.2016.2301 


\section{EXPERIMENTAL DETAIL}

\subsection{Cleaning of Silicon Wafer}

The p-type and n-type $\mathrm{Si}<100>$ substrates have been cleaned using RCA-1 and RCA-2 method to eliminate organic and ionic impurities from the surface before the films deposition. The RCA-1 solution is the combination of DI water, $\mathrm{NH}_{4} \mathrm{OH}$ and $\mathrm{H}_{2} \mathrm{O}_{2}$ in the proportion of 5:1:1, and the RCA-2 solution is combination of DI water, $\mathrm{HCL}$ and $\mathrm{H}_{2} \mathrm{O}_{2}$ in the proportion of $6: 1: 1$. To clean the samples they were dipped into RCA- 1 and RCA-2 solutions separately for 10 minutes at $80^{\circ} \mathrm{C}$ then cleaned with DI water. Further, to remove the residual oxide from the surface of the substrate sample, the samples were cleaned with buffered HF solution.

\subsection{Deposition of Bismuth Doped ZnO Thin Film}

The Bismuth doped $\mathrm{ZnO}$ sol of concentration $0.7 \mathrm{M}$ have been prepared using precursor zinc acetate dehydrate $\left(\mathrm{Zn}\left(\mathrm{CH}_{3} \mathrm{COO}\right)_{2} \cdot 2 \mathrm{H}_{2} \mathrm{O}\right)$, isopropanol (solvent) and stabilizing agent diethanolamine (DEA). The molar proportion of zinc acetate dehydrates and stabilizer DEA was kept at 1:1. For Bismuth doping we add 10 molar percentage of Bismuth nitrate pentahydrate $\left(\mathrm{Bi}\left(\mathrm{NO}_{3}\right) .5 \mathrm{H}_{2} \mathrm{O}\right.$ to the starting solution. The prepared solution was stirred at $60^{\circ} \mathrm{C}$ for 1 hour and then the prepared sol was reserved for at least 24 hours at room temperature for ageing. Further, $\mathrm{Bi}$ doped $\mathrm{ZnO}$ thin films have been deposited over n-type and p-type Si substrate by spin coating method. The films have been prepared at spinning speed of $2000 \mathrm{rpm}$ for 20 seconds, and prebaked at $100^{\circ} \mathrm{C}$ for 10 minutes in oven to evaporate the solvent and organic residuals. The deposition process has been repeated many times to obtain the required film thickness and finally the deposited films are placed in a furnace at $500^{\circ} \mathrm{C}$ for $1 \mathrm{hrs}$ with air ambient to improve the crystallization. A $250 \mathrm{~nm}$ thick aluminum circular dots have been deposited on the top of $\mathrm{ZnO}$ thin films and bottom of Si substrates using thermal evaporation method as shown in Fig.1. For the electrical characterization, I-V plot has been plotted using a semiconductor device parameter analyzer under dark condition.

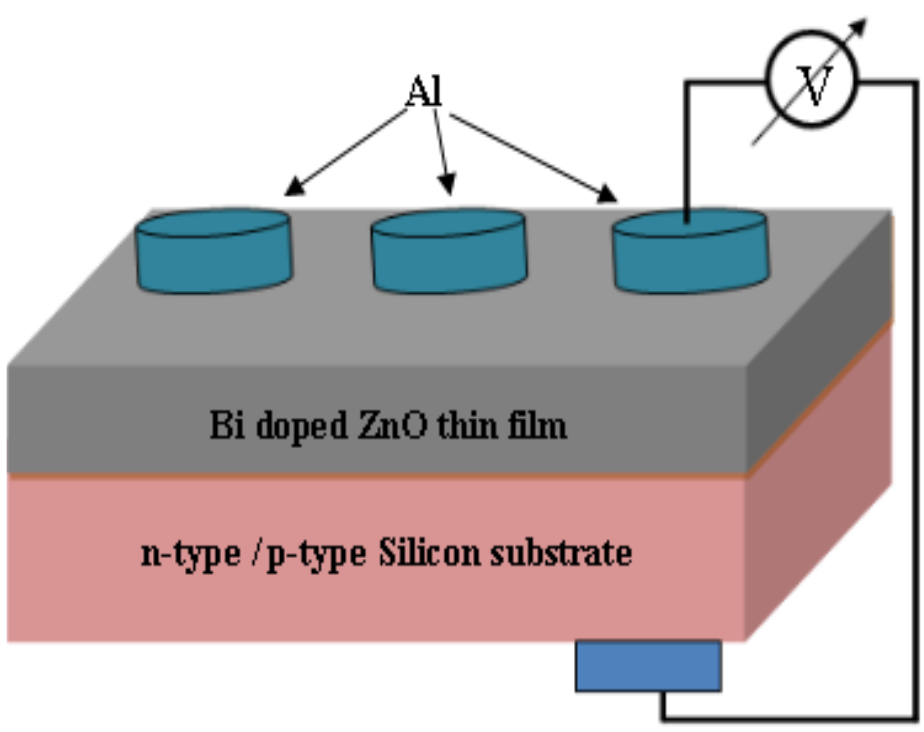

Figure 1. Schematic view of the $\mathrm{Bi}$ doped $\mathrm{ZnO}$ on $\mathrm{p}-\mathrm{Si}$ and $\mathrm{n}-\mathrm{Si}$ heterojunction. 


\section{RESULT AND DISCUSSION}

To determine the nature of majority carriers in the deposited Bi doped zinc oxide thin films a very simple and efficient hot point probe method based on seebeck effect has been performed. From the results, it can be clearly seen that $\mathrm{ZnO}$ films doped with $\mathrm{Bi}$ shows $\mathrm{p}$ - type nature. To confirm the consistency of p-type nature of $\mathrm{Bi}$ doped $\mathrm{ZnO}$ thin films, the experiment was repeated several time under same experimental condition and subsequently it have been found that outcome remains the same. The typical resistivity of the doped film as observed from hall measurement has been found to be nearly equal to $4.1 \Omega-\mathrm{cm}$.

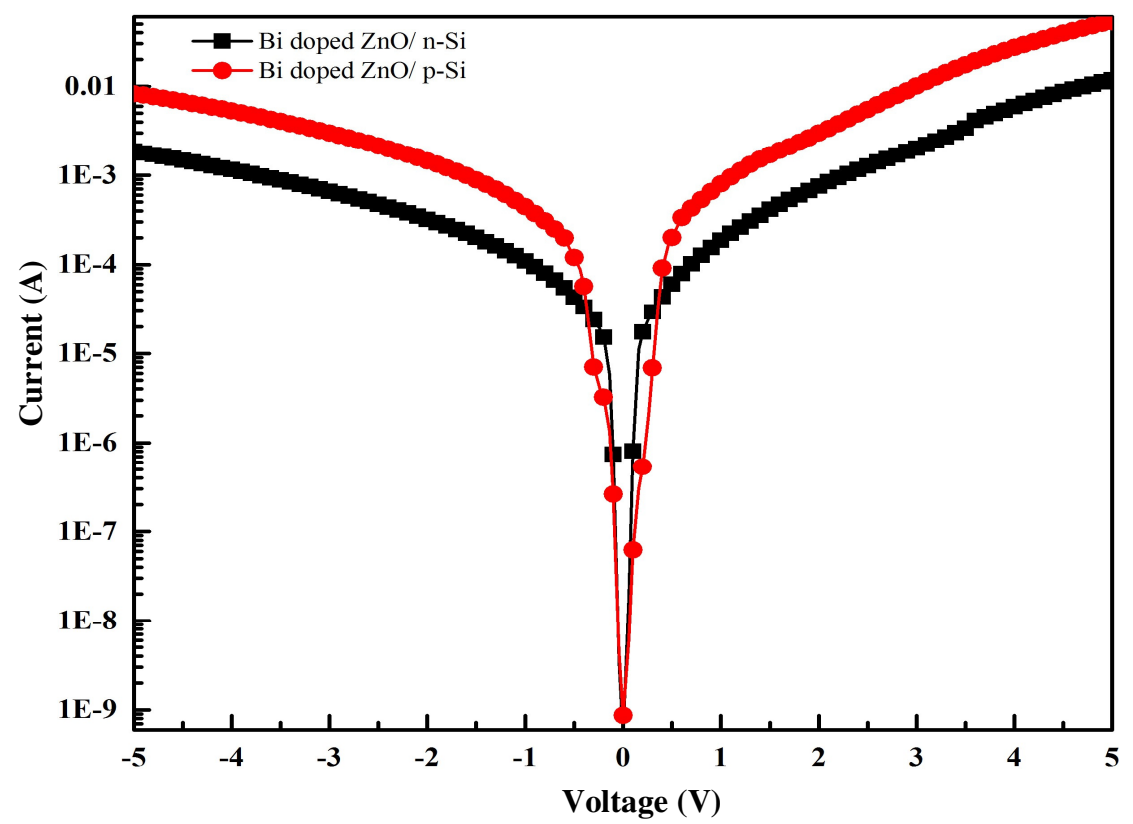

Figure 2. Current (I)-Voltage (V) characteristic Bi doped $\mathrm{ZnO} / \mathrm{p}-\mathrm{Si}$ and $\mathrm{Bi}$ doped $\mathrm{ZnO} / \mathrm{n}-\mathrm{Si}$ heterojunction

The I-V characteristic of the deposited heterojunctions have been analyzed using microprobe station and semiconductor device parameter analyzer. The semi-logarithmic I- V characteristics of p-type $\mathrm{Bi}$ doped $\mathrm{ZnO} / \mathrm{p}$-Si and p-type $\mathrm{Bi}$ doped $\mathrm{ZnO} / \mathrm{n}$-Si heterojunctions at room temperature for the voltage range between $-5 \mathrm{~V}$ to $5 \mathrm{~V}$, have been shown in Fig. 2. From the fig. 2 it is clearly observed that the fabricated heterojunctions shows good rectifying characteristics. In the p- $\mathrm{ZnO} /$ $\mathrm{n}$-si heterojunction, $\mathrm{Si}$ substrate is connected to the negative terminal of the bias source for forward biasing, while in $\mathrm{p}-\mathrm{ZnO} / \mathrm{p}-\mathrm{Si}$ heterojunction, $\mathrm{Si}$ substrate is connected to the positive terminal of the bias source for forward biasing because carrier concentration of silicon is higher than $\mathrm{Bi}$ doped $\mathrm{ZnO}$. The fabricated heterojunction shows forward biasing condition which is similar to Schottky junction. We have calculated the reverse saturation current $\left(I_{0}\right)$ by the intercept of straight line portion of $\ln (\mathrm{I})$ versus $\mathrm{V}$ plot extrapolated for voltages larger than a few KT/q with the zero voltage axis which is then used to estimate the value of barrier height $\phi_{\mathrm{B}}$. Further, the result shows very good conductivity of the films therefore it has been implicit that the Fermi level might be very closed to the valence band of doped $\mathrm{ZnO}$. The relation between current and voltage for the fabricated heterojunctions can be given as: [19]

$$
\mathrm{I}=\mathrm{I}_{0}\left(\mathrm{e}^{\mathrm{qV} \mathrm{V}} \mathrm{kT}\right)
$$


where $\mathrm{q}$ is charge on electron, $\eta$ is the ideality factor, $\mathrm{T}$ is the temperature in Kelvin, $\mathrm{K}$ is Boltzmann constant, $\mathrm{V}$ is voltage across the junction and $\mathrm{I}_{\mathrm{O}}$ is reverse saturation current.The reverse saturation current can be expressed as follow:

$$
I_{0}=A^{*} T^{2} e^{-q \Phi_{B} / k T}
$$

where $\mathrm{A}$ is junction area $\left(\mathrm{A}=0.515 \times 10^{-2} \mathrm{~cm}^{2}\right), \mathrm{A}^{*}$ is the effective Richardson constant $\left(\mathrm{A}^{*}\right.$ $=32 \times 10^{4} \mathrm{Am}^{-2} \mathrm{~K}^{-2}$ ) for $\mathrm{ZnO}$ [20] . The effective barrier height $\phi_{\mathrm{B}}$ in Eq. (2) can be calculated by using the following equation:

$$
\Phi_{B}=-\frac{\mathrm{kT}}{\mathrm{q}} \ln \left(\frac{l_{0}}{A A^{4} T^{5}}\right)
$$

From fig. 2 the calculated value of reverse saturation currents $\left(\mathrm{I}_{\mathrm{o}}\right)$ is $1.5 \times 10^{-7} \mathrm{Amp}$ for $\mathrm{p}-\mathrm{ZnO} / \mathrm{n}-\mathrm{Si}$ heterojunction and $3.3 \times 10^{-8} \mathrm{Amp}$ for $\mathrm{p}-\mathrm{ZnO} / \mathrm{p}$-Si heterojunction. Further, using calculated values of reverse saturation current and equation (3) the effective barrier height has been obtained as $\Phi_{\mathrm{bn}}$ $=0.71 \mathrm{eV}$ for $\mathrm{p}-\mathrm{ZnO} / \mathrm{n}-\mathrm{Si}$ and $\Phi_{\mathrm{bp}}=0.75 \mathrm{eV}$ for $\mathrm{p}-\mathrm{ZnO} / \mathrm{p}-\mathrm{Si}$ heterojunction. The work function of $\mathrm{ZnO}$ has been calculated based on the Schottky Mott model using following relations for heterojunctions with $\mathrm{n}-\mathrm{Si}$ and $\mathrm{p}-\mathrm{Si}$ substrate respectively.

$$
\Phi_{m}=X_{s i}+\Phi_{b n}
$$

And

$$
\Phi_{m}=E_{g}+X_{s i}-\Phi_{b p}
$$

where $E_{g}$ and $X_{\mathrm{si}}$ are the bandgap energy and electron affinity of silicon having values $1.12 \mathrm{eV}$ and $4.06 \mathrm{eV}$ [21 ]. The calculated value of the work functions for $\mathrm{p}-\mathrm{ZnO} / \mathrm{p}-\mathrm{Si}$ and $\mathrm{p}-\mathrm{ZnO} / \mathrm{n}-\mathrm{Si}$ heterojunctions are 4.43 and $4.77 \mathrm{eV}$ respectively, which closely matched with work function of defect free $\mathrm{ZnO}$ single crystal [21 ]. Since during the cleaning process of silicon wafer a very thin $(\sim 2 \mathrm{~nm})$ nonflexible insulating silicon oxide layer has been formed on the surface of silicon which tailored the barrier height. So, the barrier height with insulating $\mathrm{SiO}_{2}$ layer can be evaluated using Bardeen model which is given by [21].

$$
\begin{aligned}
& \Phi_{b n}=C\left(\Phi_{m}-X_{s i}\right)+(1-c)\left(E_{g}-\Phi_{0}\right) \text {, for n-Si wafer } \\
& \Phi_{b p}=C\left(E_{g}-\Phi_{m}+X_{s i}\right)+(1-c)\left(\Phi_{0}\right), \text { for p-Si wafer }
\end{aligned}
$$

Where,

$$
C=\frac{s_{i}}{s_{1} \| q^{2} \delta D_{s}}
$$

and $\delta$ is the thickness of $\mathrm{SiO}_{2}$ layer, $\mathrm{D}_{\mathrm{s}}$ is density of states and $\varepsilon_{\mathrm{i}}$ is total permittivity, $\phi_{\mathrm{o}}$ is the neutral Fermi level. For a given interfacial layer thickness, $\left(\phi_{\mathrm{bP}}+\phi_{\mathrm{bn}}\right)=\mathrm{E}_{\mathrm{g}}$, due to the similarity of the surface state in $\mathrm{p}$ and $\mathrm{n}$ type Si. Using the values of $\mathrm{q}^{D}{ }_{s=2} \times 10^{12} / \mathrm{cm}^{3}$ for $\mathrm{n}$-si wafer, $\delta=1.5 \mathrm{~nm}$ and $\varepsilon_{\mathrm{i}}=3.9, \phi_{\mathrm{o}}=0.27 \mathrm{eV}$ from the work reported by Turner et al. [22] for metal $/ \mathrm{n}-\mathrm{Si}$ Schottky barrier and the work function of $\mathrm{ZnO}$ as calculated in this experiment by equation (3) the value of $\phi_{\mathrm{bn}}$ has been evaluated using equation (6) and has been obtained as $0.76 \mathrm{eV}$. Similarly, using the values of $\mathrm{qD}_{\mathrm{s}}=3 \times 10^{12} / \mathrm{cm}^{3}$ for $\mathrm{p}-\mathrm{Si}$ wafer, and $\phi_{\mathrm{o}}=0.33 \mathrm{eV}$ from the work 
reported by Smith et al. [23], $\phi_{\text {bp }}$ has been calculated using equation (7) obtained as $0.72 \mathrm{eV}$. Further, due to the presence of thin $\mathrm{SiO}_{2}$ layer between silicon wafer and $\mathrm{ZnO}$ film it is observed that $\phi_{\mathrm{bP}}$ decreases and $\phi_{\mathrm{bn}}$ increases as compared to the Schottky Mott model approach. The high temperature deposition of film increases the rate of oxide formation on the surface of silicon hence reducing the density of state which decreases the value of $\phi_{\mathrm{bP}}$ for $\mathrm{p}$-Si device and increases the value of $\phi_{\mathrm{bn}}$ for $\mathrm{n}-\mathrm{Si}$ devices. The variation in barrier height with temperature may be due to the fact that at high temperature more oxygen diffuses toward $\mathrm{Si}$ interface which makes $\mathrm{ZnO}$ less stoichiometric by which oxygen induced defects in $\mathrm{ZnO}$ decreases the work function of $\mathrm{ZnO}$ which in due course decreases the barrier height.

\section{CONCLUSIONS}

In this paper, $\mathrm{Bi}$ doped $\mathrm{p}-\mathrm{ZnO}$ thin films have been deposited on $\mathrm{pSi}$ and $\mathrm{nSi}$ substrate using solgel spin coating technique. The work function of bismuth doped $\mathrm{ZnO}$ thin film have been obtained from the electrical properties of $\mathrm{p}-\mathrm{ZnO} / \mathrm{p}-\mathrm{Si}$ and $\mathrm{p}-\mathrm{ZnO} / \mathrm{n}-\mathrm{Si}$ heterojunctions. The calculated value of the work function based on the Schottky barrier model exhibits value between 4.5 and $4.78 \mathrm{eV}$ for the films. The effect of very thin layer of $\mathrm{SiO}_{2}$ at the interface of $\mathrm{ZnO}$ and $\mathrm{Si}$ wafer on the variation of barrier height, have also been analyzed.

\section{ACKNOWLEDGEMENTS}

Authors are grateful to the Centre for Interdisciplinary Research (CIR), MNNIT Allahabad for providing characterization facilities.

\section{REFERENCES}

[1] A. Singh, And H. L. Vishwakarma,(2014) "An Existential Study On Structural, Optical And Electronic Properties Of Zno Nanoparticles And Nanorods", Iosr Journal Of Applied Physics, Vol.6, No. 2, Pp28-32.

[2] P. Gopal, And N. A. Spaldin,(2006) "Polarization, Piezoelectric Constants, And Elastic Constants Of Zno, Mgo, And Cdo", Journal Of Electronic Materials, Vol. 35,No. 4, Pp538-542.

[3] C. Jagadish, And S. J. Pearton,(2011) Eds. Zinc Oxide Bulk, Thin Films And Nanostructures: Processing, Properties And Applications .

[4] J. Zang, C. M. Li, X. Cui, J. Wang, X. Sun, H. Dong, And C. Q. Sun,(2007) Tailoring Zinc Oxide Nanowires For High Performance Amperometric Glucose Sensor",Electroanalysis, Vol.19,No.9, Pp1008-1014.

[5] L. Wang, Z. Lou, T. Fei, And T. Zhang,(2011) "Zinc Oxide Core-Shell Hollow Microspheres With Multi-Shelled Architecture For Gas Sensor Applications”, Journal Of Materials Chemistry Vol.21, Pp19331-19336.

[6] D. R. Sahu, Shin-Yuan Lin, And Jow-Lay Huang,(2006) "Zno/Ag/Zno Multilayer Films For The Application Of A Very Low Resistance Transparent Electrode", Applied Surface Science ,Vol.252,No. 20, Pp7509-7514

[7] J. X. Wang, X. W. Sun, A. Wei, Y. Lei, X. P. Cai, C. M. Li And Z. ～Dong, (2006)." Zinc Oxide Nanocomb Biosensor For Glucose Detection ",Applied Physics Letters ,Vol.88,No.23, Pp3106

[8] J. Zhang, S. Wang, M. Xu, Y. Wang, B. Zhu, S. Zhang, W. Huang And S. Wu,(2009) "Hierarchically Porous Zno Architectures For Gas Sensor Application”, Crystal Growth And Design, Vol.9,No.8, Pp3532-3537.

[9] Ken C. Pradel, Wenzhuo Wu, Yusheng Zhou, Xiaonan Wen, Yong Ding, And Zhong Lin Wang,(2013) "Piezotronic Effect In Solution-Grown P-Type Zno Nanowires And Films", Nano Letters ,Vol.13, No.6, Pp2647-2653. 
[10] S.B. Zhang, S.H. Wei And A. Zunger,(2001) "Intrinsic N-Type Versus P-Type Doping Asymmetry And The Defect Physics Of Zno", Physical Review ,Vol. 63,No.7,Pp 075205.

[11] T.H. Minami, H. Sato, H. Nanto And S. Takata,(1985), “ Group Iii Impurity Doped Zinc Oxide Thin Films Prepared By Rf Magnetron Sputtering”, Japanese Journal Of Applied Physics, Vol.24,No.10, Pp1781.

[12] D.B. Laks, C.G. Van De Walle, G.F. Neumark, And S.T. Pantelides,(1993) “Acceptor Doping In Znse Versus Znte", Applied Physics Letters, Vol.63,No.10, Pp1375-1377.

[13] S. J. Pearton, D. P. Norton, K. Ip, Y. W. Heo And T. Steiner,(2005) "Recent Progress In Processing And Properties Of Zno", Progress In Materials Science, Vol.50,No.3,Pp293-340

[14] T. Yamamoto, And H. K. Yoshida,(1999) "Solution Using A Codoping Method To Unipolarity For The Fabrication Of P-Type Zno."Japanese Journal Of Applied Physics, Vol.38, No.2b, Ppl166.

[15] Z. Jin, T. Fukumura, M. Kawasaki, K. Ando, H. Saito, T. Sekiguchi, Y. Z. Yoo, M. Murakami, Y. Matsumoto, T. Hasegawa And H. Koinuma,(2001) “ High Throughput Fabrication Of TransitionMetal-Doped Epitaxial Zno Thin Films: A Series Of Oxide-Diluted Magnetic Semiconductors And Their Properties", Applied Physics Letters,Vol.78,No.24, Pp3824-3826.

[16] B. K. Singh And Shweta Tripathi,(2015) "Fabrication And Characterization Of Au/P-Zno Schottky Contacts", Superlattices And Microstructures,Vol.85, Pp697-706 .

[17] B. K. Singh And Shweta Tripathi,(2015) "Influence Of Bi Concentration On Structural And Optical Properties Of Bi Doped P-Type Zno Thin Films Prepared By Sol-Gel Method", Journal Of Materials Science: Materials In Electronics,Vol.27,No.3, Pp2360-2366.

[18] F.Chouikh, Y. Beggah And M. S. Aida,(2011) "Optical And Electrical Properties Of Bi Doped Zno Thin Films Deposited By Ultrasonic Spray Pyrolysis", Journal Of Materials Science: Materials In Electronics,Vol. 22, No. 5, Pp499-505.

[19] J.I. Pankove, (1971) "Optical Processes In Semiconductors”, Vol. 88, Prentice-Hall, New Jersey.

[20] H. V. Wenksten, E. M. Kaidashev, M. Lorentz, H. Hochmuth, G. Biehne, J. Lenzer, V. Gottscalch, R.Pickenhain And M. Grundmann,(2004) "Lateral Homogeneity Of Schottky Contacts On N-Type Zno", Applied Physics Letters, Vol.84, Pp 79.

[21] S. M. Sze,(1981) "Physics Of Semiconductor Devices”, Wiley, New York.

[22] M.J. Turner And E.H. Rhoderick,(1968) "Metal-Silicon Schottky Barriers", Solid- State Electron, Vol.11,No.3, Pp 291-300.

[23] B.L. Smith And E.H. Rhoderick,(1971) "Schottky Barriers On P-Type Silicon", Solid- State Electron, Vol. 14,No.1, Pp 71-75.

\section{Authors}

Brijesh Kr. Singh received the B.Tech degree in Electronics and Instrumentation engineering from the Institute of Engineering and Technology, Lucknow (IET, Lucknow), UP, India in 2002 and the M.Tech (Hons.) degree in Control and Instrumentation from National Institutes of Technical Teachers' Training and Research (NITTTRs), Chandigarh, India in 2012. Since 2013, he is working toward the Ph.D. degree in electronics and communication engineering from Motilal Nehru National Institute of Technology Allahabad, (U.P.) India. His research interests include Fabrication of doped and undoped $\mathrm{ZnO}$ thin films for Electronics and optoelectronics applications.

Lucky Agarwal received the B.Tech. degree in Electronics and Communication Engineering from Gautam Buddh Technical University, Lucknow, India, in 2010 and the M.Tech degree in Microelectronics and VLSI Design from Motilal Nehru National Institute Of Technology, Allahabad, India in 2014. He has awarded gold medal for getting 1 st rank in Microelectronics and VLSI Design. He is currently pursuing PhD from Motilal Nehru National Institute of Technology, Allahabad, India. His research interests include Fabrication and simulation of optical semiconductors devices.
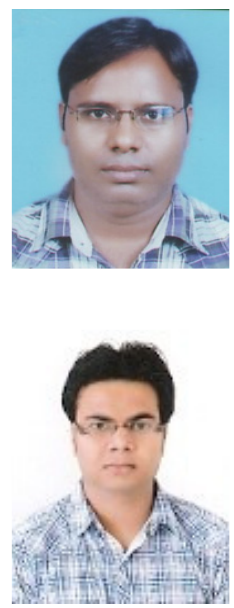
Shweta Tripathi earned her Ph.D. degreefrom the Department of Electronics Engineering, Indian Institute of Technology (IIT), Banaras Hindu University (BHU), Varanasi, India in 2011. Dr. Tripathi has joined the Department of Electronics \& Communication Engineering, Motilal Nehru National Institute of Technology (MNNIT) Allahabad, as Assistant Professor in 2012.Dr. Tripathi has published more than 30 papers in various peer reviewed international journals and conference proceedings. Her present research interests include modeling and simulation of optically controlled microwave devices and circuits, short-channel MOSFETs, multiple-gate MOSFETs, Fabrication of electronic and photonic

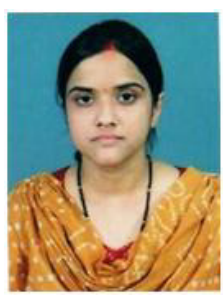
devices etc. Dr. Tripathi is the life time member of Indian Society for Technical Education (M. No. : LM90626), India. 